\title{
Modelling and optimization of the removal chromium from natural water destined for human alimentation
}

\begin{abstract}
This paper concerns the removal of chromium from natural water destined for human alimentation. In order to define the best conditions as well to suggest possibilities for the removal of chromium, we have used the optimization method to determine the optimal conditions of water with a minimum of chromium. A rotatable central composite design is set up for checking the effect of four variables after determination of the physical and chemical factors such a temperature, $\mathrm{pH}$, conductivity and redox potential. It is concluded that the level of chromium largely depends on the temperature, conductivity and redox potential, and that working at precise conditions of these factors can optimize the chromium removal.
\end{abstract}

Keywords: chromium, aqueous environment, natural water, optimization, experimental design
Volume 3 Issue I - 2019

\author{
Rahma Bchitou, Nabih Zerki, Karima Achelhi, \\ Ahmed Bouhaouss \\ Nanostructures Laboratory, Process Engineering and \\ Environment, Department of Chemistry, Faculty of Sciences, \\ University Mohammed V-Agdal, Morocco
}

Correspondence: Nabih Zerki, Nanostructures Laboratory, Process Engineering and Environment, Department of Chemistry, Faculty of Sciences, University Mohammed V-Agdal, Rabat, Morocco, Email nabih_smc@hotmail.com

Received: December 04, 2018 | Published: January 28, 2019

\section{Introduction}

Chromium is useful in a great number of industrial applications. ${ }^{1,2}$ Some of its compounds are toxic to most organisms. ${ }^{3}$ The world-wide use of chromium has resulted in the release of toxic compounds in many industrial and densely populated areas where it constitutes a threat for human health and biota in aqueous environment. ${ }^{4}$ To evaluate and to treat the problems related to chromium contamination, an understanding of the chromium redox in surface water is needed. Thus, traces of chromium in natural water cannot be understood without knows the effect of some factors on the analysis. Currently, there are only few rate factors available for environmental conditions, which would allow modelling of chromium redox reactions. In order to check the effect of some factors on chromium levels in natural water destined for human alimentation, we have been proposed to determine the effect of $\mathrm{pH}$, temperature, conductivity and redox potential. ${ }^{5-7}$ The goals of this study are to study the effect of environmental conditions on the various levels of chromium, which would allow modelling of that metal. Experimental designs offer an excellent approach to reduce the charge and time by limiting the number of experiments; furthermore this methodology gives a high quality of information. To determine the optimal experimental conditions, the response surface method can be employed..$^{8-13}$ The approach we used is that of carrying out a rotatable orthogonal central composite design. ${ }^{14-16}$ in 4 factors. Our study was realised on the Sebou river upstream Kariat Ba Mohamed, and downstream the city of Fes (Morocco), which show a high content of pollutants mostly heavy metals.

\section{Experimental methodology}

The water samples was acidified since the taking by addition of the nitric acid to which the $\mathrm{pH} \approx 1$ for analyse the metals in water. The dilutions and the preparation of the solutions were done with the ultrapure water. The measurements of chromium in water samples were performed by atomic absorption spectroscopy (Varian AA 20). The survey of the experimental design, and the statistical calculations were carried out by JMP softwar. ${ }^{17}$

\section{Choice of plan}

We used an experimental strategy that could give as knowledge of choice of every factor on the evolution of experimental response. A rotatable orthogonal central composite design was chosen to evaluate the factors that significantly influence the level of chromium in river water and what levels of the factors are needed to produce optimal water destined for human alimentation. The experimental matrix restraint was constructed from a central composite experimental design. This was achieved with the isovariance by rotation and the uniform precision (the variance of centre of domain is equal to the variance in all point situated in the interior of a sphere of which radius $\alpha$ is the biggest distance of central point). This matrix presents many advantages, particularly a strong resolution and a minimum number of tests. ${ }^{16}$ For four factors, the realisation of a complete factorial design to five levels requires $54=625$ experiences, while the central composite design requires 31 experiences. ${ }^{8}$ However the realisation of that depends from the number of variables to study and it is greatly bound to the chosen protocol and this could not be extended to the realisation of experiences where the new variables could intervene. This method consists of the variation of natural variables as: temperature, $\mathrm{pH}$, conductivity and redox potential and to raise the interactions (or between them and their influences on the response measured that in our case is the concentration of chromium.

\section{Choice of the studied factors}

Several factors intervene on the purity of the natural water destined for human alimentation. We selected those that could have the biggest influence on the results of the analyses of chromium after have made some exploratory experiences. So, the acquaintances already acquired on the method, we were brought to choose four factors. These factors are a priori the most influential on the content of chromium measured in the natural water by atomic absorption spectroscopy without flame.

\section{Methodology}

This paper discusses the principles governing the construction and analysis of the type of experimental design. 31 experiments are used to estimate the model coefficients. The corresponding four variables central composite designs are shown in Table $1 \&$ Table 2. The 31 experiments can be divided into three groups as follows:

a. 16 for the plan fractional factorial; 
b. 8 for the points in stars at distance $\pm \alpha$ from the centre. The distance $\alpha$ is calculated so as to obtain rotatability. A four variables central composite design is rotatable if $\alpha= \pm 2$;

c. 7 for the experiments carried out on the centre of the experimental domain to obtain orthogonality and isovariance by rotation properties. The experiments repeated at the centre of domain. ${ }^{15}$

Then, we made some tests of significance of the coefficients of model by the criteria of isovariance by rotatio ${ }^{11}$ in order to separate the non-significant factors. And finally, we defined the optimisation of the influential factors. In order to assess this method, the value of the raw such responses the concentration of chromium trace doesn't have interest in oneself directly because of the difference between the maximum and the minimum. ${ }^{11}$ We carried out a transformation of the experimental response to create other response that could take them into account simultaneously. ${ }^{16}$ The function of transformation to which corresponds the best of these objectives is the decimal logarithm of the experimental response $(\mathrm{Z})$ multiplied by $10^{5}$ :

$$
Y=\log \left(Z x 10^{5}\right)
$$

With Z: the concentration of chromium in $\mathrm{mg} \cdot \mathrm{L}^{-1}$.

This was verified with the analysis of Screening, which allows to perform (or to obtain) the transformation of Box-Cox. ${ }^{11,16}$ This analysis was used also in order to evaluate the most significant effects and interactions.

\section{Experimental domain and results}

The experimental domain of the 4 factors studied is given in Table 1. The levels of the factors were selected in such a way that limits of some conditions who could be met. The matrix and the obtained response values of $\mathrm{Z}$ are reported in the Table 2. The 31 observed responses are used to compute the model coefficients using the least square method. This function writes under the general following shape:

$Y=b_{0}+b_{1} X_{1}+\ldots+b_{4} X_{4}+b_{11} X_{1}^{2}+\ldots+b_{44} X_{4}^{2}+b_{12} X_{1} X_{2}+\ldots+b_{34} X_{3} X_{4}$

Where $\mathrm{Y}$ is the response, $\mathrm{Xi}$ the factors and bij the coefficients of each term calculated by multiple regression analysis. ${ }^{8,12,15}$ The results of the coefficients of model and the Student test values are reported in the Table 3 .

Table I Variables and experimental domain

\begin{tabular}{lllllll}
\hline Variable & $\mathbf{- 2}$ & $\mathbf{- 1}$ & $\mathbf{0}$ & $\mathbf{1}$ & $\mathbf{2}$ & $\begin{array}{l}\text { Variation } \\
\text { pace }\end{array}$ \\
\hline $\mathrm{X}_{1}: \mathrm{T}\left({ }^{\circ} \mathrm{C}\right)$ & 15 & 20 & 25 & 30 & 35 & 5 \\
$\mathrm{X}_{2}: \mathrm{pH}$ & 6 & 7 & 8 & 9 & 10 & 1 \\
$\mathrm{X}_{3}:$ Cond. $\left(\mu \mathrm{S} . \mathrm{cm}^{-1}\right)$ & 500 & 750 & 1000 & 1250 & 1500 & 250 \\
$\mathrm{X}_{4}:$ Red. Pot. $(\mathrm{mV})$ & 100 & 150 & 200 & 250 & 300 & 50
\end{tabular}

\section{Analysis of variance and the validation of the model}

The principle of the exploitation of the results rests on the analysis of the variance. ${ }^{16}$ Indeed, the analysis of variance is carried out for each response presenting an interest for the study. The software appraises the repeatability in the centre of interest and uses this evaluation in order to value with a test of Student (Sado \& Sado M, 1991), the significance of the coefficients calculated. The results of this analysis are given in the Table $3 \&$ Table 4 . The statistical tests showed that the model established for the response explains the experimental results well. The model could be used in order to make some forecasting in the experimental domain and the interpretation of the results. We can, then, conclude that at $90 \%$, (probability level of confidence), alone the coefficients $b_{0}, b_{3}, b_{13}, b_{33}$ and $b_{44}$ are significant. This allows us to write the resulting estimated models as follows:

$$
\begin{aligned}
Y= & 2.00+0.32 X_{3}-0.37 X_{1} X_{3}+0.35\left(X_{3}\right)^{2}+0.26\left(X_{4}\right)^{2} \\
& (+0,24)(+0,01)(+0,02)(+0,12)(+0,09)
\end{aligned}
$$

with: $\mathrm{X}_{1}$ : temperature

$\mathrm{X}_{3}$ : conductivity

\begin{tabular}{|c|c|c|c|c|c|c|}
\hline No & $\mathbf{X}_{1}$ & $\mathrm{X}_{2}$ & $\mathbf{X}_{3}$ & $\mathrm{X}_{4}$ & Z: $[\mathrm{Cr}]\left(\mathrm{mg} . \mathrm{L}^{-1}\right)$ & $\log \left(\mathrm{Z} .10^{5}\right)$ \\
\hline 1 & + & + & + & + & 0.0292 & 3.46 \\
\hline 2 & + & + & + & - & 0.0100 & 3.00 \\
\hline 3 & + & + & - & + & 0.0130 & 3.11 \\
\hline 4 & + & + & - & - & 0.0130 & 3.11 \\
\hline 5 & + & - & + & + & 0.0180 & 3.25 \\
\hline 6 & + & - & + & - & 0.0160 & 3.20 \\
\hline 7 & + & - & - & + & 0.0210 & 3.32 \\
\hline 8 & + & - & - & - & 0.0280 & 3.44 \\
\hline 9 & - & + & + & + & 0.0180 & 3.25 \\
\hline 10 & - & + & + & - & 0.0080 & 2.90 \\
\hline 11 & - & + & - & + & 0.0001 & 1.00 \\
\hline 12 & - & + & - & - & 0.0001 & 1.00 \\
\hline 13 & - & - & + & + & 0.0280 & 3.48 \\
\hline 14 & - & - & + & - & 0.0060 & 2.78 \\
\hline 15 & - & - & - & + & 0.0010 & 2.00 \\
\hline 16 & - & - & - & - & 0.0030 & 2.48 \\
\hline 17 & -2 & 0 & 0 & 0 & 0.0020 & 2.30 \\
\hline 18 & 2 & 0 & 0 & 0 & 0.0001 & 1.00 \\
\hline 19 & 0 & -2 & 0 & 0 & 0.0001 & 1.00 \\
\hline 20 & 0 & 2 & 0 & 0 & 0.0020 & 2.30 \\
\hline 21 & 0 & 0 & -2 & 0 & 0.0040 & 2.60 \\
\hline 22 & 0 & 0 & 2 & 0 & 0.0320 & 3.50 \\
\hline 23 & 0 & 0 & 0 & -2 & 0.0060 & 2.78 \\
\hline 24 & 0 & 0 & 0 & 2 & 0.0040 & 2.60 \\
\hline 25 & 0 & 0 & 0 & 0 & 0.0010 & 2.00 \\
\hline 26 & 0 & 0 & 0 & 0 & 0.0010 & 2.00 \\
\hline 27 & 0 & 0 & 0 & 0 & 0.0010 & 2.00 \\
\hline 28 & 0 & 0 & 0 & 0 & 0.0010 & 2.00 \\
\hline 29 & 0 & 0 & 0 & 0 & 0.0010 & 2.00 \\
\hline 30 & 0 & 0 & 0 & 0 & 0.0010 & 2.00 \\
\hline 31 & 0 & 0 & 0 & 0 & 0.0010 & 2.00 \\
\hline
\end{tabular}

$\mathrm{X}_{4}$ : redox potential.

Table 2 Matrix and responses measured 
Table 3 The model coefficients and Student test

\begin{tabular}{cllll}
\hline Coeff. & Estimate & Std. error & T ratio & Prob $>/ \mathbf{t} /$ \\
\hline $\mathrm{b}_{0}$ & 2.000 & 0.243 & 8.22 & 0.000 \\
$\mathrm{~b}_{1}$ & 0.185 & 0.131 & 1.41 & 0.176 \\
$\mathrm{~b}_{2}$ & -0.019 & 0.131 & -0.15 & 0.881 \\
$\mathrm{~b}_{3}$ & 0.318 & 0.131 & 2.42 & 0.028 \\
$\mathrm{~b}_{4}$ & 0.024 & 0.131 & 0.19 & 0.856 \\
$\mathrm{~b}_{11}$ & 0.002 & 0.120 & 0.02 & 0.985 \\
$\mathrm{~b}_{22}$ & 0.002 & 0.120 & 0.02 & 0.985 \\
$\mathrm{~b}_{33}$ & 0.353 & 0.120 & 2.93 & 0.009 \\
$\mathrm{~b}_{44}$ & 0.262 & 0.120 & 2.18 & 0.045 \\
$\mathrm{~b}_{12}$ & 0.126 & 0.160 & 0.78 & 0.447 \\
$\mathrm{~b}_{13}$ & -0.373 & 0.160 & -2.32 & 0.034 \\
$\mathrm{~b}_{14}$ & -0.009 & 0.160 & -0.06 & 0.953 \\
$\mathrm{~b}_{23}$ & 0.185 & 0.160 & 1.15 & 0.267 \\
$\mathrm{~b}_{24}$ & 0.043 & 0.160 & 0.27 & 0.789 \\
$\mathrm{~b}_{34}$ & 0.134 & 0.160 & 0.83 & 0.418 \\
\hline $\mathrm{b}_{4 A}$ & & & & \\
\hline
\end{tabular}

Table 4 Analysis of variance

\begin{tabular}{lllll}
\hline Source & $\begin{array}{l}\text { Degree of } \\
\text { freedom }\end{array}$ & $\begin{array}{l}\text { Sum of } \\
\text { square }\end{array}$ & $\begin{array}{l}\text { Mean } \\
\text { square }\end{array}$ & F ratio \\
\hline Model & 14 & 11.832 & 0.845 & 2.041 \\
Error & 16 & 6.626 & 0.414 & Prob $>$ F \\
C total & 30 & 18.458 & & 0.086 \\
Lack of fit & 10 & 6.626 & 0.663 & $\cdot$ \\
Pure error & 6 & 0 & 0 & Prob $>$ F \\
Total error & 16 & 6.626 & & $\cdot$ \\
\hline
\end{tabular}

The relationship (3) is used to plot the curves of the isoreponses. These curves are helpful in studying the effects of the variation of the factors in the domain studied and in determining the optimal conditions. The graphical representation of the results permits a better visualisation of the effects of different factors. Figures 1 \& Figure 2 plot the isoreponses curves obtained for the concentration of chromium, respectively in the plan [temperature $\left(\mathrm{X}_{1}\right)$. conductivity $\left(\mathrm{X}_{3}\right)$ ] and [conductivity $\left(\mathrm{X}_{3}\right)$. redox potential $\left(\mathrm{X}_{4}\right)$ ], with $\mathrm{X}_{2}$ fixed at 0 . From examining the Figure 2, we can note that the amount of chromium increases essentially when the conductivity is lower 750 $\mu \mathrm{S} . \mathrm{cm}^{-1}$ when the temperature is lower to $15^{\circ} \mathrm{C}$ and for a $\mathrm{pH}$ fixed to 8 . The contour plots in this figure shows that the optimum of chromium can be obtained for a conductivity situated between 1000 and $1250 \mu{\mathrm{s} . \mathrm{cm}^{-1}}^{-1}$ for a redox potential situated between 150 and 200 $\mathrm{mV}$ for $\mathrm{pH}$ fixed at 8 and a temperature fixed at $25^{\circ} \mathrm{C}$. In contrast the influence of $\mathrm{pH}$ presents a negative effect. But the interaction of this factor with the conductivity is not negligible. However, the optimization of the removal Chromium from natural water destined for human alimentation will depend on only some measures of some physical and chemical parameters, but also of the stability of these factors to the course of the analysis of the heavy metals especially by spectroscopy of atomic absorption methods without flame.

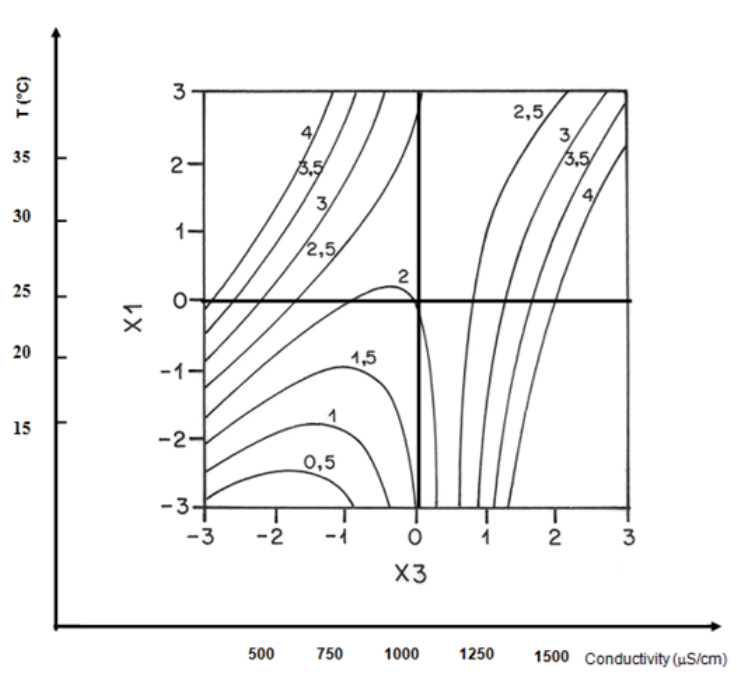

Figure I Isoreponse curves of chromium (XI:Temperature; $X 3$ : Conductivity), with $\times 2=0$ and $\times 4=0$.

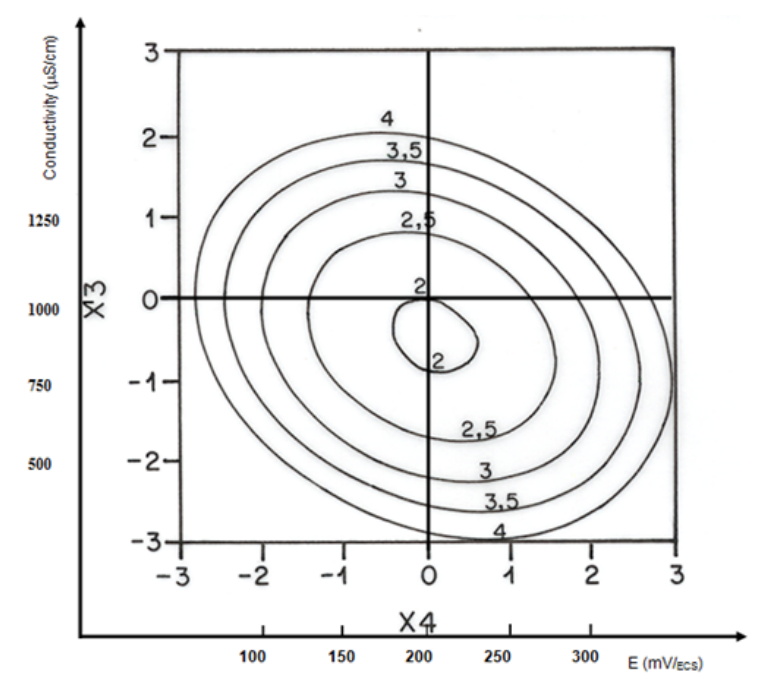

Figure 2 Isoreponse curves of chromium (X3: Conductivity; X4: redox potential E), with $X 1=0$ and $X 2=0$.

\section{Conclusion}

This work has allowed to optimizing the removal chromium from natural water destined for human alimentation. The response surface equation for chromium removal was established. The strategy chosen, a rotatable orthogonal central composite design was suitable to point on the main significant effect and to determine the optimal conditions of utilization and removal. So, only the temperature, the conductivity and the redox potential governs the level of chromium. It would be interesting to develop the research of the heavy metals dissolves, particulate and dissolved matter in order to specify and value the quantities of the heavy metals analysed in the natural water by spectroscopy of atomic absorption. The amount of chromium increases essentially when the conductivity is lower to $750 \mu \mathrm{S} . \mathrm{cm}^{-1}$ for a redox potential situated between 150 and $200 \mathrm{mV}$ for $\mathrm{pH}$ fixed at 8 and a temperature fixed at $25^{\circ} \mathrm{C}$.

\section{Acknowledgments}

None 


\section{Conflicts of interest}

The author declares that there is no conflicts of interest.

\section{References}

1. Ramakrishnaiah CR, Prathima B. Hexavalent chromium removal from industrial wastewater by chemical precipitation method. International Journal of Engineering Research and Applications. 2012;2(2):599-603.

2. Studnicki A, Kilarski J, Przybył M, et al. Wear resistance of chromium cast iron - research and application. Journal of Achievements in Materials and Manufacturing Engineering. 2006;16(1-2):63-74.

3. Reena S, Neetu G, Anurag M, et al. Heavy metals and living systems: An overview. Indian Journal of Pharmacoly. 2011;43(3):246-253.

4. Rowbotham AL, Levy LS, Shuker LK. Chromium in the environment: an evaluation of exposure of the UK general population and possible adverse health effects. Journal of Toxicology and Environmental Health. 2000;3:145-178.

5. Bchitou R, Bouhaouss A, Foutlane A. The exchange of phosphorus and nitrogen ions in water-sediment interface in Sebou River (Morocco). Physical and Chemical News. 2006;31:99-105.

6. Bewley RJF, Jeffries R, Watson S, et al. An Overview of Chromium Contamination Issues in the South-East of Glasgow and the Potential for Remediation. Environmental Geochemistry and Health. 2001;23(3):267-271.

7. Zerki N, Bchitou R, Bouhaouss A. Characterization of some trace elements in natural waters of the Bouregreg estuary (Rabat, Morocco) by a chemometric study. Physical and Chemical News. 2011;59:121-126.
8. Goupy J, Murray M. Reduce the costs of computer simulation thanks to the design of experiments: an example in calculation. Rev Info. 1991;37(1):5-22.

9. Hug SJ, Buerge IJ, Weidler PG. Transformation of chromium in the environment. Analusis. 1997;25(7):12-15.

10. Bchitou R, Hamad M, Heughebaert JC, et al. Application of a center composite experiments plan to evaluate the natural water system for human consumption. Vecteur Environnement. 2003;36(1):79-82.

11. Goupy J. Experimental Plans, Engineering Techniques, Treatise Chemical Analysis and Characterization. Dunod Paris. 1992;1-20.

12. Mathieu D, Phan TLR. Experimental Research Methodology, Experimental Strategy and Biotechnological Processes. Lavoisier, Editor. Tech Doc Paris. 1995;1-10.

13. Zerki N, Bouhaouss A, Bchitou R. Modeling and optimization the effect of some anions on the water conductivity. Australian Journal of Basic and Applied Sciences. 2012;6(10):396-402.

14. Myers RH, Khuri AI, Carter WH. Response surface methodology. Technometrics. 1988;31(2):137-157.

15. Montgomery DC. Design and analysis of experiments. John Wiley, Editor. New York NY: USA. 1992.

16. Box GE, Draper NR. Empirical model-building and response surfaces. Wiley/Interscience. New York, NY, USA. 1987;521-535.

17. SAS Institut. JMP Version 3.2 Introduction guide, User's guide and Statistic and Graphics Guide. USA : SAS Support. 1995. 